\title{
TRADISI MOTONG MUNGGEL DI KABUPATEN TASIKMALAYA UNTUK BAHAN PEMBELAJARAN MEMBACA ARTIKEL DI SMA (Kajian Struktural dan Semiotik)
}

\author{
Mu'min Ishak Ramdhani \\ SMA Al Muttaqin Tasikmalaya \\ Pos-el: m.ishak.ramdhani@gmail.com
}

\begin{abstract}
Abstrak
Latar belakang dari penelitian ini adalah kurangnya pengetahuan masyarakat pada tradisi motong munggel, baik itu masyarakat Kabupaten Tasikmalaya secara khusus ataupun masyarakat Jawa Barat secara umumnya. Adapun tujuan dari penelitian ini adalah untuk mendeskripsikan mengenai (1) sejarah tradisi motong munggel, (2) langkah-langkah dalam tradisi motong munggel, (3) unsur semiotik dalam tradisi motong munggel, dan (4) bahan ajar membaca artikel tradisi motong munggel. Metode yang digunakan dalam penelitian ini yaitu metode kualitatif desktiptif dengan teknik observasi, wawancara, dan dokumentasi. Instrumen yang digunakan dalam penelitian ini yaitu pedoman wawancara dan kartu data. Hasil dari penelitian ini adalah; pertama, sejarah mengenai tradisi motong munggel, dimana tradisi ini mulai dilaksanakan di Desa Jayamukti kurang lebih sejak tahun 1989; kedua, adanya langkah-langkah dalam tradisi motong munggel terdiri dari tiga bagian yaitu langkah-langkah sebelum, langkah-langkah saat berlangsung, dan langkahlangkah setelah berlangsungnya tradisi motong munggel; ketiga, tanda yang ditemukan dalam tradisi motong munggel berjumlah 23 tanda, yang terdiri atas 14 ikon, indeks sebanyak 6 , dan simbol sebanyak 3; keempat, hasil dari penelitian ini bisa dijadikan sebagai bahan pembelajaran membaca artikel budaya di SMA kelas XII. Tradisi motong munggel merupakan suatu tradisi yang harus dilestarikan. Selain dari memiliki tujuan, nilai-nilai dan tanda-tanda yang memiliki makna bagi kehidupanpun dapat dijadikan sebagai bahan pembelajaran membaca artikel di SMA kelas XII.
\end{abstract}

Kata Kunci: strukturalisme dan semiotika, tradisi motong munggel, membaca artikel

\section{THE TRADITION OF MOTONG MUNGGEL IN TASIKMALAYA FOR TEACHING AND LEARNING ARTICLE READING MATERIAL IN SENIOR HIGH SCHOOL (STRUCTURAL AND SEMIOTIC STUDY)}

\begin{abstract}
The background of this study was the lack of knowledge on Motong Munggel tradition of Tasikmalaya people in particular and West Java people in general. The purpose of this study was to describe all aspects of Motong Munggel tradition include; (1) the history, (2) the steps (3) the semiotic elements, and (4) reading article teaching and learning materials. The method used in this research was the descriptive qualitative method with observation, interview, and documentation techniques. The instruments used in this study were interview guidelines and data cards. The results of this study are as it follows: first, the history revealed that tradition of Motong Munggel began to be practiced in Jayamukti village since 1989; second, the steps in the Motong Munggel tradition consist of three parts, i.e. the preceding steps, in progress step, and the steps after Motong Munggel performed; third, there were 23 signs found consisted of 14 icons, six indexes, and three symbols; fourth, the results of this study can be used as teaching and learning material for cultural article reading of Grade XII Senior High School students. Motong Munggel is a
\end{abstract}


tradition that has to be preserved. Besides it has meaningful goals, values and signs that have for people life it can also be used as teaching and learning material.

Keywords: structuralism and semiotics, Motong Munggel tradition, reading articles

\section{PENDAHULUAN}

Manusia dalam menghadapi lingkungan selalu menggunakan berbagai model tingkah laku yang selektif (selected behaviour) sesuai dengan tantangan lingkungan yang dihadapinya. Salah satu strategi adaptasi manusia untuk menguasai lingkungannya ialah strategi di bidang kesehatan. Strategi tersebut tumbuh dan berkembang dalam upaya manusia mencegah dan mengobati penyakit. Hal ini sesuai dengan pernyataan Foster \& Anderson (dalam Sianipar, dkk., 1992, hlm. 2) yang menyebutkan bahwa dalam menghadapi penyakit ini manusia telah mengembangkan suatu pengetahuan yang luas dan komplek, yang mencakup kepercayaan, teknik, peranan, norma, nilai, ideologi, sikap kebiasaan, ritus, dan berbagai lambang (simbol) yang satu sama lain bertalian erat dan membentuk suatu kekuatan, yang lazim disebut sebagai etiologi penyakit (etiology of illness).

Adanya sikap yang selektif merupakan suatu strategi adaptasi sosial budaya sebagai respon terhadap ancaman dari suatu penyakit yang menyerang dirinya ataupun anggota masyarakatnya. Beda halnya dengan hewan, manusia tidak akan tega meninggalkan atau mengisolasi salah satu anggota masyarakat yang terserang penyakit, melainkan bersama-sama membantu mencari obat yang bisa menyembuhkannya.

Setiap masyarakat memiliki sistem kesehatan yang beda-beda sesuai dengan latar belakang masyarakat itu sendiri. sistem kesehatan merupakan suatu kumpulan ide, nilai, serta praktek yang teratur dan berarti, terutama dalam konteks budaya tertentu dari mana sistem itu berkembang (Kleinmann dalam Sianipar, dkk., 1992, hlm. 3).

Indonesia yang terdiri dari berbagai macam suku bangsa dan latar belakang budaya yang berbeda-beda, identik dengan berbagai tradisi yang hidup dan berkembang serta menjadi ciri khas tertentu untuk suatu masyarakat.

Kata "tradisi" berasal dari bahasa Latin tradere atau traderer yang secara bahasa artinya mengirimkan, menyerahkah, dan memberikan untuk diamankan. Secara umum tradisi merupakan ide, keyakinan, atau perilaku di masa lampau yang diturunkan secara simbolis kepada suatu kelompok ataupun tertentu. (Langlois, dalam Liliweri, 2014, kc. 97).

Di Jawa Barat yang tidak bisa terlepas dari masyarakat Sunda, tentunya memiliki sebuah tradisi yang biasa dilaksanakan dalam kehidupan sehariharinya baik yang berupa kesenian tradisi ataupun yang bentuknya upacara tradisi. Salah satu tradisi yang sampai sekarang masih hidup adalah tradisi motong munggel yang ditemukan di Desa Jayamukti Kecamatan Pancatengah Kabupaten Tasikmalaya. Tradisi ini dipercaya oleh masyarakatnya sebagai suatu sistem kesehatan yang dilaksanakan ketika ada anggota keluarga atau masyarakatnya yang terserang penyakit keturunan. Ada kepuasan tersendiri ketika ada masarakat yang terserang peyakit keturunan yang kemudian diobati dengan tradisi motong munggel. Selain ada obat-obatan yang diberikan oleh yang mengobati, adanya sugesti yang kuat dari masyarkat bahwa tradisi ini bisa menyembuhkan penyakit keturunanan, menjadikan alasan tradisi ini masih bisa bertahan sampai sekarang. 
Namun, seiring dengan berkembangnya zaman dan pola pikir masyarakat, secara tidak langsung berdampak pada sikap masyarakat terhadap sebuah tradisi yang hidup di lingkungan sekitarnya. Begitu pula sikap masyarakat Desa Jayamukti dalam upaya menjaga dan melestarikan tradisi motong munggel. Meskipun tradisi motong munggel masih hidup sampai sekarang, tetapi keadaanya mulai kurang dikenal oleh masyarakat umum. Baik itu mengenal bentuk dari tradisinya ataupun mengetahui nilai-nilai yang terkandung di dalamnya. Kurangnya kesadaran masyarakat dalam menjaga dan melestarikan kebudayaan jadi penyebab hilangnya pengetahuan tentang kebudayaan di masyarakat. Selain itu, pelaku aktif yang biasa melaksanakan tradisi motong munggel semakin berkurang, padahal tradisi ini tramasuk tradisi yang jarang ditemukan dan mempunyai nilai-nilai yang tinggi.

Dalam rangka meneliti tradisi motong munggel beserta nilai-nilai yang terkandung di dalamnya, peneliti menggunakan pendekatan Strukturalisme Claude Lévi-Strauss dan pendekatan semiotika yang diprakarsai oleh Ferdinand de Saussure dan Charles Sanders Peirce's. Piliang (2010, hlm. 20) menyebutkan bahwa strukturalisme adalah pekerjaan intelektual yang berkaitan dengan struktur pemikiran dan tingkah laku manusia, selanjutnya mempunyai paham bahwa totalitas yang kompleks hanya bisa dipahami sebagai satu rangkaian unsur-unsur yang saling mempengaruhi. Sedangkan istilah 'semiotik' berasal dari bahasa Yunani, semeion, yang artinya 'tanda' selanjutnya semiotika diartikan sebagai ilmu tanda. Pengertian ini dikembangkan kembali menjadi salah satu cabang ilmu yang mempelajari tanda dan segala sesuatu yang berkaitan dengan tanda, seperti sistem tanda, sistem tanda dan proses yang berlaku dalam pemakaian tanda
(Sudjiman dalam Koswara, 2010, hlm. 194).

Peirce menyebutkan bahwa tanda merupakan sesuatu yang dapat diinterprétasi atau ditafsirkan (dalam Sulasman dan Gumilar, 2013, hlm. 179). Sedangkan Berger menyebutkan bahwa:

Tanda adalah sesuatu yang terdiri pada sesuatu yang lain atau menambah dimensi yang berbeda pada sesuatu, dengan memakai apapun yang dapat dipakai untuk mengartikan sesuatu yang lainnya. C.S. Peirce menyebut tanda sebagai "suatu pegangan seseorang akibat keterkaitan dengan tanggapan atau kapasitasnya" (dalam Berger, 2010, hlm. 1)

Untuk memperkenalkan kembali tradisi motong munggel agar tidak punah, salah satu caranya adalah melalui pendidikan. Pendidikan mempunyai fungsi yang begitu penting untuk mewariskan nilai-nilai kebudayaan dari generasi ke generasi selanjutnya. Hal ini sesuai dengan pendapat Kosasih (1989, hlm. 1) yang menyebutkan bahwa pendidikan itu khususnya pengajaran budaya, merupakan usaha sadar untuk mencapai tujuan pada pemusatan perubahan tingkah laku siswa. Dalam proses pembelajaran, peran guru dan siswa sangat penting. Guru sebagai subjek dalam proses pembelajaran mempunyai peran dan fungsi untuk menarik minat siswa agar mempunyai rasa bangga, menjaga, dan melestarikan kebudayaan. Tujuannya tentu agar siswa mempunyai sikap yang positif. Selain itu, tujuan pembelajaran dapat tercapai jika guru terampil dalam memilih bahan ajar, terampil dalam milih dan menganalisis buku sumber yang sesuai dengan tujuan pembelajaran, serat dapat menentukan tingkat kemampuan siswa sesuai dengan waktu yang disediakan.

Setelah mengamati penelitianpenelitian sebelumnya, belum ada penelitian tentang tradisi motong munggel. Padahal tradisi ini termasuk 
pada tradisi yang mempunyai nilai-nilai tinggi serta merupakan aset budaya yang harus dilestarikan. Selain itu, hasil dari penelitin ini dapat dijadikan karya tulis mengenai kebudayaan serta dapat dipakai sebagai bahan pembelajaran agar tradisi yang diteliti dapat dikenal oleh masyarakat umum dan generasi selanjutnya, utamanya generasi yang berada di lembaga pendidikan formal (sekolah). oleh sebab itu, penelitian ini diberi judul "Tradisi Motong Munggel di Desa Jayamukti Kecamatan Pancatengah Kabupaten Tasikmalaya untuk Bahan Pembelajaran Membaca Artikel di SMA kelas XII (Kajian Struktural dan Semiotik)" perlu dilaksanakan.

\section{METODE}

Metode yang digunakan dalam penelitian ini adalah metode deskriptif dengan pendekatan kualitatif. Penelitian kualitatif biasanya disebut juga penelitian naturalistik, karena penelitiannya berpusat pada keadaan yang sifatnya alamiah (natural setting). Hal ini selaras dengan pendapat Sugiyono (2011, hlm. 89) yang menyebutkan bahwa metode penelitian kualitatif adalah metode penelitian yang berdasar pada falsafah postpostivisme, digunakan untuk meneliti suatu kondisi alamiah, dimana peneliti menjadi kunci dari instrumen penelitiannya, teknik mengumpulkan data dilakukan secara triangulasi (gabungan), analisis data mempunyai sifat induktif/ kualitatif, dan hasil penelitian kualitatif lebih cenderung pada makna dari pada generelisasi.

Sumber data yang digunakan dalam penelitian ini yaitu, (1) data dari sesepuh tradisi motong munggel, (2) data dari pihak desa untuk mendapat data tentang gambaran umum/ profil tempat yang dijadikan lokasi penelitian, (3) data dari beberapa orang di Kampung Sindangjaya yang mengetahui serta pernah melaksanakan tradisi motong munggel, dan (4) data dari perawat untuk menambah informasi tentang penyakit keturunan.

Teknik yang digunakan dalam penelitian ini yaitu observasi, wawancara, dan dokumentasi. Adapun instrumen yang digunakan yaitu pedoman wawancara dan kartu data. Instrumen ini digunakan sebagai pegangan peneliti untuk mencari data atau informasi di lapangan. Serta mengolah data yang didapat yang selanjutnya dianalisis dan membagi unsur-unsur menggunaka kartu data. Selain itu, kartu data juga dipakai sebagai pedoman untuk menyesuaikan hasil penelitian berdasarkan pada kriteria bahan pembelajaran membaca artikel.

\section{HASIL DAN PEMBAHASAN}

Tradisi motong munggel pertama di dibawa ke kampung Sindangjaya oleh Ibu Ikoh yang sekarang menjadi sesepuh dalam tradisi ini, dari desa tetangganya yaitu Desa Tonjong yang berada di sebelah barat Desa Jayamukti. Lahirnya tradisi motong munggel di Desa Jayamukti tidak melewati komunikasi secara langsung seperti yang dilaksanakan dari guru dan murid, tapi secara tidak langsung ketika Ibu Ikoh sedang berada di tempat kerja, ada yang mengobrol bahwa jika ada keluarga yang terkena penyakit keturunan harus dipotong punggel.

Sebuah tradisi adalah pengetahuan yang sudah menjadi kebaiasaaan dan diwariskan secara turun temurun. Hal ini sesuai dengan pendapat Murgiayanto yang menyebutkan bahwa: Tradisi memperlihatkan bagaimana anggota masyarakat bertingkah laku, baik dalam kehidupan yang bersifat duniawi maupun terhadap hal-hal yang bersifat gaib atau keagamaan. Tradisi juga dipahami sebagai pengetahuan, doktrin, kebiasaan, praktik, dan lain-lain yang diwariskan secara turun-temurun (dalam Zulfa dan Kaksim, 2014, hlm. 59).

Tradisi motong munggel pertama dilaksanakan \pm tahun 1989. Hitungan ini 
dikaitkan dengan hitungan lahir pasien yang pertama diobati ditambah umur ketika pasien diobati. Eem (pasien yang pertama diobati) lahir tahun 1984 (12/10), sedengkan diobati ketika berumur 5 tahun, jadi jika tahun lahir 1984 ditambah 5 tahun $(1984+5=1989)$ hasilnya yaitu 1989.

Motong munggel terdiri dari dua suku kata yaitu motong dan munggel. Danadibrata (2009, hlm. 542) kata motong berasal dari potong yang berarti tidak menyambung lagi sebagaimana mestinya pada sesuatu yang menyambung. Sedangkan kata punggel, munggel yaitu kata pekerjaan memotong atau memenggal pohon yang masih berdiri kira-kira di tengah-tengahnya; menebang pohon pisang supaya buahnya tidak rusak harus di-punggel terlebih dahulu saat menebangnya; menebang pepohonan yang tinggi di sekitar rumah (Danadibrata, 2009 kc. 549).

Setiap tradisi mempunyai tujuan masing-masing yang ingin dicapai, baik itu dalam tradisi yang berupa kesenian ataupun tradisi yang diungkapkan dalam sebuah upacara, termasuk dalam tradisi motong munggel. Tradisi ini dilaksanakan ketika ada masyarakat yang sakit. Baik itu sakit karena ada faktor keturunan, wabah penyakit, perubahan cuaca (naturalistik) ataupun penyakit yang dikarenakan adanya gangguan mahluk gaib, ataupun ada perantara lain (personalistik) terutama penyakit keurunan seperti mengi, jantung, diabetes dll. Supaya penyakit yang pernah dialami oleh nenek moyangnya tidak ditularkan kepada generasi seterusnya.

Selain mempunyai tujuan tertentu, suatu tradisi juga mempunyai fungsi yang tidak akan bisa dipisahkan dari tradisi itu sendiri. Rostiati, dkk. (dalam Nugraha, 2011, hlm. 26) menyebutkan bahwa upacara adat mempunyai dua fungsi, yaitu fungsi spiritual dan fungsi sosial.

Menurut Ikoh (wawancara, 24 Januari 2017), tradisi motong munggel mempunyai fungsi sebagai ungkapan untuk meminta pertolongan kepada Alla $\mathrm{h}$ swt. agar dijauhkan dari marabahaya dan penyakit yang gampang ditemukan dari lingkungan, utamanya penyakit yang berkaitan dengan keturunan. Selain itu, tradisi ini sebagai hadiah kepada para nenek moyang dengan cara tawasulan yang dibacakan dalam bahasa Arab serta ditujukan kepada Allah swt., para nabi, para wali dan para nenek moyang.

Berdasarkan hasil wawancara di atas, tradisi motong munggel mempunyai fungsi seperti di bawah ini.

1) Tradisi motong munggel sebagai kegiatan syukuran serta meminta perlindungan kepada yang Maha Kuasa dari segala gangguan dan penyakit yang datang.

2) Tradisi motong munggel berkaitan dengan rasa hormat kepada arwaharwah nenek moyang yang disebut dalam do'a atau tawasul yang dilaksanakan.

3) Mempertahankan tradisi motong munggel berarti secara tidak langsung meneurskan apa yang biasa dilakukan nenek moyangnya.

4) Tradisi motong munggel merupakan sarana untuk menumbuhkan rasa tanggung jawab. Hal ini berkaitan dengan aturan-aturan yang harus dilaksanakan dan yang tidak boleh dilaksanakan.

\section{Pelaksanaan Tradisi Motong Munggel.}

Dalam pelaksanaan tradisi motong munggel, di dalamnya menggunakan tumpeng yang dijadikan sebagai media utama. Dimana bahan dasar pembuatan tumpeng tersebut, diharuskan menggunakan beras yang berasal dari dua tempat, yaitu dari sawah dan huma. Dengan catatan, kalau beras putih dari sawah, maka beras merah harus dari huma. Atau sebaliknya, bila beras merah dari sawah, beras putih harus dari huma. Hal ini dikaitkan dengan kepercayaan masyarakat yang menganggap bahwa penyakit kebanyaan terdapat dari dua unsur (air dan tanah) 
dan juga berasal dari makanan pokok yang dimakannya setiap hari.

Pelaksanaan tradisi motong munggel dibagi ke dalam tiga tahapan, yaitu: tahapan sebelum berangsung (persiapan), tahapan ketika berlangsung, dan tahapan setelah berlangsungnya tradisi motong munggel.

\section{Tahapan sebelum berlangsungnya tradisi motong munggel (perisapan)}

Berdasarkan hasil observasi tanggal 19 april 2017, yang dilakukan dalam tahapan ini adalah dimulai dari mencari bahan-bahan yang akan digunakan, terutama yang akan diapakai dalam pembuatan tumpeng yang dipakai sebagai media utama dalam tradisi ini. Tahapan ini antara lain, mencari bahanbahan, menumbuk (nutu) padi, napian beras, mencuci berasa (ngisikan), mengukus beras, membuat bumbu atau rempah-rempah, ngarih, dan mengukus gigih.

Dalam peroses persiapan, selain melihat bahan-bahan yang digunakan, peneliti juga melihat barang-barang atau perabotan yang digunakan. Perabotanperabotan itu antara lain: dulang, halu, nyiru, boboko, aseupan, sééng, baskom, pangarih, parud, péso (pisau) raut, daun pisang, tumpeng, beras merah (huma) beras putih (sawah), telur ayam kampung, dan bumb/ rempah-rempah.

\section{Tahapan ketika berlangungnya tradisi motong munggel}

Berdasarkan hasil observasi, kegiatan yang dilakukan dalam pelaksanaan tradisi motong munggel adalah berdo'a atau tawasulan, memotong tumpeng di tiga tempat, dan membaca do'a penutup.

a. Tawasulan, yang utama dalam kegiatan ini adalah mendo'akan para arwah nenek moyang yang sudah lebih dulu meninggal dunia, terutama nenek moyang yang semasa hidupnya menderita penyakit yang sama dengan keterunannya saat ini.
Tujuannya, supaya penyakit yang pernah dialami tersebut, tidak diwariskan (ditularkan) lagi kepada generasi selanjutya.

b. Memotong tumpeng di tiga tempat. Setelah selesai berdo'a (tawasulan), kegiatan seanjutnya yaitu memotong tumpeng dengan menggunakanan pisau raut di tiga tempat. Tempat tersebut antara lain (1) di rumah bagian tengah, (2) di samping rumah atau di tempat mengalirnya air dari atap rumah (panyawéran), (3) di persimpangan jalan (jalan cagak) yang ada disekitaran rumah yang sedang diobati. Kegiatan ini dimaksudkan supaya bisa membersihkan penyakit yang ada di rumah, menangkal penyakit yang datang dari langit melalui air hujan, dan penyakit yang mungkin didapat ketika pasien bepergian ataupun ada rang lain yang melewati jalan di sekitaran rumahnya. Pada saat memotong tumpeng, yang mengobati biasanya dibarengi dengan membaca surat AL-Ikhlas (3X), Al-Falaq (1X), An-nass (1X), dan ayat Qursyi (7X).

c. Setelah selesai berdo'a (tawasulan) dan memotong tumpeng di tiga tempat, dilanjutkan dengan membacakan do'a penutup. Seperti halnya dalam sebuah upacara atau tadisi yang lain biasa diawali dengan do'a dan diakhiri pula dengan do'a. Kalaupun dalam sebuah upacara adat diawali dengan rajah pamuka dan ditutup dengan rajah pamunah, dalam tradisi motong munggel juga dibuka dengan tawasulan dan ditutup dengan do'a penutup. Tujuannya supaya tradisi yang akan dilaksanakan bisa dilancarkan dan tercapainya tujuan yang diharapkan. Selain itu do'a dalam tradisi ini dimaksudkan untuk meminta pertolongan ataupun perlindungan kepada Alloh Swt., dan yang paling utama bisa diesmbuhan dan daijauhkan dari penyakit keturunan. 
Sehingga penyakit itu hanya sampai pada dirinya, dan kelak tidak diwariskan kepada anak cucunya.

\section{Tahapan setelah berlangsungnya tradisi motong munggel}

Setelah selesai membacakan do'a penutup, bukan berarti menjadi bagian trakhir dari tradisi ini. Melainkan, dilanjutkan dengan membagikan tumpeng yang sudah dipotong dan dibungkus kepada masyarakat atau tetangga yang ada disekitar rumah yang sedang melaksanakan tradisi motong munggel. Disebagian masyrakat, ketika selesai motong munggel biasanya dilanjutkan dengan mengadakan syukuran di rumah (ngariung). Yang dimaksud dengan syukuran di sini, yaitu mengundang sodara dan tetangga ke rumah untuk mengadakan riungan, kemudian dipimpin oleh ustad atau sesepuh kampung. Mengadakan syukuran (ngariung) bukanlah perkara wajib yang harus dilaksanakan detekah motong munggel tetapi atas inisiatif keluarga yang diobati, kalau mampu ya dianjurkan, tapi kalu tidak ampu tidak disarankan untuk memaksakan.

Dibagikannya tumpeng yang menjadi media dalam tradisi motong munggel, bukan berarti untuk menyebarkan peyakit yang sedang diderita. Tapi sebagai ungkapan saling berbagi dan sekaligus meminta do'a dari masyarakat yag ada supaya yang diobati bisa lekas sembuh dan sehat kembali.

\section{Unsur-unsur semiotik dalam tradisi motong munggel}

Dalam tradisi motong munggel terdapat beberapa unsur yang saling berkaitan dan saling mempengaruhi satu sama lain, sehingga menjadi datu kesatuan yanhg tidak bisa dipisahkan dan dibentuk dalm satu rangkaian tradisi, yaitu tradisi motong munggel. unsurunsur yang terdapat dalam tradisi memiliki arti tertentu yang menjadi satu kesepakatan dari sesepuh dan arga masyarakat yang mengenal tradisi ini. Arti-arti tersebut dapat dianalisis menggunakan ilmu tanda yang diprakarsai oleh Charles Sanders Peirce's. Teori semiotika Peirce (dalam Sobur, 2013, hlm. 157) yang dimaksud dengan tanda (sign) dibagi ke dalam tiga bagian, yaitu: ikon (icon), indeks (index), dan simbol (symbol).

Dari hasil analisis menganai tanda yang terdapat dalam tradisi motong munggel, ditemukan ada 23 tanda yang mencakup ikon yang berjumlah 14, indeks yang jumlahnya 6 , dan simbol yang jumlahnya 3 . Tanda-tanda tersebut dihimpun dalam satu kesatuan yang tidak bisa dipisahkan satu sama lain. Tandaanda tersebut labih jelasnya seperti yang terdapat dalam uraian di bawah ini.

\section{Ikon dalam tradisi motong munggel}

Ikon merupakan tanda yang menggambarkan persamaan dari satu hal yang sudah dikenal sebelumnya, tanda itu berupa fisik (2 atau 3 dimensi) yang hampir mirip dengan hal yang direpresentasikan berdasarkan persamaannya (Mulyana dalam Sobur, 2013, hlm. 158)

Ikon yang ditemukan dalam tradisi motong munggel jumlahnya ada14 tanda, di antaranya adalah; (1) sesepuh, (2) wakil sesepuh, (3) péso raut, (4) Dulang, (5) Halu, (6) Nyiru, (7) Boboko, (8) aseupan, (9) Sééng, (10) Baskom, (11) Pangarih, (12) Daun Cau, (13) Tumpeng, jeung (14) Béas beureum.

Istilah-istilah tersebut disebut ikon sebab, merupakan persamaan atau hal yang direpresentasikan berdasarkan persamaannya, seperti contoh istilah Sesepuh. Sesepuh dalam tradisi motong munggel merupakan pengganti untuk sebutan kepada seseorang yang bisa memimpin tradisi motong munggel, tanpa memperhitungkan sesepuh tersebut lakilaki ataupun perempuan. Contoh yang lain, misalnya istilah tumpeng. Tumpeng dalam tradisi motong mjunggel merupakan istilah pengganti dari berbagai 
racikan makanan dari ulai beras merah dan beras putih, telur, bumbu/ rempahrampah dan bahan-bahan lain yang terdapat di dalamnya. Selain itu, contoh yang lainya adalah istilah beras merah. Beras merah dalam tradisi motong munggel merupakan salah satu gambaran dari makanan pokok yang disukai nenek moyang. Beras merah merupakan ikon, sebab menunjukan bahwa beras tersebut berasal dari ladang (huma).

\section{Indeks dalam tradisi motong munggel}

Indeks adalah tanda yang secara asosiatif merupakan sebab akibat, ada hubungannya antara acuan dengan sipat yang tetap. Seperti contoh, kata rokok indeksna adalah asap. Hubungan indeksikal antara rokok dan asap beralangsung sebab adanya hubungan yang tetap antara rokok dan asap. Katakata yang memiliki hubungan indeksikal memiliki ciri pokok masing-masih yang sipantna individual. Setiap satu ciri dengan ciri yang lainnya memiliki sipat yag berbeda-beda dan tidak bisa saling bergantian. Misalkan ciri pokok yang terdapat di dalam rokok tidak akan pernah sama dengan ciri pokok yang terdapat dalam asap (Sobur, 2013, hlm. 159).

Dalam tradisi motong munggel terdapat 6 indeks, diantaranya yaitu; (1) tradisi motong munggel. Disebut indeks sebab tradisi ini mengacu kepada suatu penyakit yang menyerang anggota keluarga. Selain itu, dalam prlaksanaan tradisi motng munggel menggunakan tumpeng sebagi media utama yang merupakan gabungan dari baha-bahan yang disukai para nenek moyang terdahulu. Jadi dilaksanakannya tradisi motong munggel akibat adanya penyakit keturunan; (2) ruang tengah rumah (tengah imah). Disebut indek sebab dilaksanakannya pemotongan ditempat ini merupakan akibat dari adanya angapan bahwa penyakit datang dari keluarga sendiri ataupun rang lain yang masuk ke rumah; (3) samping rumah (panyawéran). Disebut indeks, sebab dilaksanakannya pemotongan tumpeng di tempat ini merupakan akibat dari adanya anggapan/ kepercayaan yang mengangap bahwa penyakit itu juga bisa turun dari langit melalui hujan; (4) persimpangan jalan (jalan cagak). Disebut indeks, sebab merupakan akibat dari adanya anggapan bahwa penyakit ada kemungkinan dibawa dari jalan yang suka digunakan bepergian ataupun jalan pulang menuju rumah. Selain itu aada kemungkinan penyakit yang diderita dibaw oleh orang lain yang pernah melewati jalan sekitar rumah; (5) tawasulan, dilaksanakan tawasulan merupakan ungkapan do'a supaya para arwah nenek moyang mendapatkan keselamatan dari Alloh Swt., jeung (6) do'a penutup, dilaksanakannya do'a penutup merupakan ungkapan dari rasa syukur, memohon pertolongan, dan meminta keselamatan kepada Alloh Swt.

\section{Simbol dina tradisi motong munggel}

Secara etimologis, kata simbol asalnya dari bahasa Yunani sym-ballein yang artinya barang atau tingkah laku (perbuatan) yang dikaitkan dengan suatu ide atau gagasan (Hartoko dan Rahmanto dalam Sobur, 2013, hlm. 155). Sedangkan menurut Berger (2010, hlm. 27) simbol, dari prespektif Saussurean, adalah jenis tanda di mana hubungan antara penanda dan petanda seakan-akan bersifat arbitrer.

Dalam tradisi motong munggel terdapat simbol yang jumlahnya ada 3, diantaranya yaitu; (1) béas beureum, hal ini dikarenakan dengan dipakainya bahan ini merupakan simbol dari kehidupan manusia yang berasal dari darat; (2) béas bodas, bahan dasar tumpeng ini merupakan simbol dari kehidupan manusia yang bergantung pada air; (3) endog hayam kampung. Hal ini dikarenakan telur dianggap sebagai cikal baka kehidupan, dan dalam hal ini telur yang selalu terpisah antara bagian kuning dan putihnya sebagai simbol pemisah antara nenek moyang dan keturunannya. 


\section{Bahan ajar membaca artikel tradisi motong munggel}

Tim pengembang MKDP

Kurikulum dan Pembelajaran (2015, hlm. 152) menjelaskan bahwa bahan atau materi pembelajaran merupakan "isi" dari kurikulum, yaitu bidang studi yang dilengkapi dengan topik/sub topik serta perinciannya. Selain itu, kalau digolongkan berdasarkan teori taksonomi Bloom, dkk. Bahan pembelajaran meliputi aspek kogintif (pengetahuan), afektif (sikap/nilai), dan psikomotor (keterampilan)/ sedangkan Haerudin dan Kardana (2013, hlm. 77) menyebutkan bahwa bahan ajar merupakan salah satu komponen yang bisa mendukung tercapainya tujuan pembelajaran.

Cara memilih bahan ajar sangatlah diperluka, sebab pembelajaran tidak bisa dilaksanakan dengan baik apabila semua bahan yang diajarkan tidak ada batasannya. Nasution (dalam Haerudin dan Kardana, 2013, hlm. 77) menjelaskan bahwa bahan ajar harus dipilih berdasarkan lima hal, yaitu (1) tujuan yang ingin dicapai, (2) dianggap memiliki nilai untuk kehidupan manusia, (3) dianggap memiliki nilai sebagai warisan dari generasi sebelumnya, (4) ada gunanya untuk menguasai suatu keilmuan, dan (5) sesuai dengan kebutuhan dan minat siswa.

Berdasarkan kriteria bahan ajar di atas, hasil dari penelitian ini, yang dibuat kedalam bentuk arrtikel sesuai dan bisa dijadikan alternatif bahan ajar membaca artikel di SMA kelas XII. Hal ini dikarenakan hasil penelitian sesuai dengan tujuan yang ingin dicapai, dianggap memiliki nilai-nilai untuk kehidupan manusia, memiliki nilai-nilai sebagai warisan dari generasi sebelumnya, ada manfaat untuk menguasai suatu bidang keilmuan, dan sesuai dengan kebutuhan dan minat siswa.

\section{SIMPULAN}

untuk $\begin{gathered}\text { Penelitian ini memiliki tujuan } \\ \text { menganalisi }\end{gathered}$ mendeskripsikan objek yang dikaji oleh peneliti, yang kemudian dikaitkan dengan bahan ajar di sekolah. Objek dalam penelitian ini adalah "Tradisi Motong Munggel", dengan menggunakan pendekatan Struktural dan Semiotik sebagai bidang kajian, serta hasilnya dijadikan sebagai salah satu arlernatid bahan aja maca artikel di SMA kelas XII.

Berdasarkan hasil penelitian, tradisi motong munggel mangrupa tradisi yang biasa dilakukan masarakat Kampung Sindangjaya Desa Jayamukti Kecamatan Pancatengah Kabupaten Tasikmlaya ketika ada anggota keluarganya yang menderita penyakit keturunan.

Dalam tradisi motong munggel terdapat beberapa unus yang memiliki tanda-tanda serta arti tertentu. Berdasarkan hasil analisis tanda yang terdapat dalam tradisi motong munggel jumlahnya ada 23 tanda, meliputi ikon yang jumlahnya 14, indeks 6 , jeung simbol 3. Ikon yang ditemukan dalam tradisi motong munggel kebanyakan berkaitan dengan pelaku, alat perlengkapan, dan makanan yang ditemukan ketika berlangsungnya tradisi. Indeks, diidentikan dengan tradisi motong munggel itu sendiri, tempat berlangsungnya, dan do'a yang dibacakan. Sedangkan simbol merupakan bagian utama dari tradisi motong munggel, yang mana artinya disetujui oleh sesepuh tradisi serta diikuti oleh masyarakat yang menggunakannya.

Dikaitkan dengan bahan ajar, hasil dari penelitian mengenai tradisi motong munggel bisa memenuhi kriteria yang terdapat dalam memilih dan menyusun bahan ajar. Unsur-unsur yang terdapat dalam tradisi motong munggel memiliki nilai nilai tinggi yang baik untuk sarana pembentukan karakter siswa di sekolah melalui pemahaman tergadap sebuah tradisi. 


\section{DAFTAR PUSTAKA}

Berger, Arthur Asa. (2010). Pengantar Sémiotika: Tanda-tanda dalam Kebudayaan Kontemporer. Yogyakarta: Tiara Wacana.

Danadibrata, R.A. (2009). Kamus Basa Sunda. Bandung: PT Kiblat Buku Utama.

Haerudin, Dingding \& Kardana, Kosim (2013). Panganteur Talaah Buku Ajar. JPBD FPBS UPI

Kosasih, Dede (1989). Karakteristik Tokoh Utama dina Novel Karya Ahmad Bakri pikeun Bahan Aparesiasi di SPG (Skripsi). JPBD, FPBS, IKIP Bandung.

Koswara, Dedi (2010). Sastra Sunda Buhun. Bandung : JPBD FPBS UPI ; Wahana Karya Grafika.

Liliweri, Alo. (2014) Pengantar Studi Kebudayaan. Bandung : Nusamedia

Nugraha, I. (2011) Ajén Sosiologi dina Tradisi Upacara adat Ngalaksa di Désa Rancakalong Kacamatan Rancakalong Kabupatén Sumedang pikeun Bahan Pangajaran Maca di SMA Kelas XII. (Skripsi). JPBD FPBS, UPI Bandung.

Piliang, Yasraf Amir. (2010). Sémiotika dan HiperSémiotika: Gaya, Kode dan Matinya Makna. Bandung: Matahari.
Sianipar, T. Spk. (1992). Dukun, Mantra, dan Kepercayaan

Masarakat. PT. Grafikatama Jaya.

Sobur, Alex. (2013). Sémiotika Komunikasi. Bandung: Remaja Rosdakarya.

Sugiyono. (2011). Metode Penelitian Kuantitatif, Kualitatif, dan $R \& D$. Bandung: CV. Alfabeta.

Sulasman \& Gumilar, S. (2013). Teoriteori Kebudayaan dari Teori Hingga Aplikasi. Bandung: Pustaka Setia.

Tim pengembang MKDP Kurikulum dan Pembelajaran. (2013). Kurikulum dan Pembelajaran. Jakarta: PT Raja Grafindo Persada.

Zulfa dan Kaksim. (2014). Sistem Pola Pewarisan Tradisi Malamang Di Kota Padang. (Jurnal Kajian Budaya Vol. 10. No. 20, Juli 2014) sadia di: http://ojs.unud.ac.id/index.php/kajia n/article/view/13872

\section{UCAPAN TERIMA KASIH}

Terimakasih penulis sampaikan kepada semua pihak yang telah membantu penelitian ini, terutama kepada Penyunting Jurnal Lokabasa atas dimuatnya tulisan ini. 